\title{
Entrepreneurial activity, risk, and the business cycle*
}

\author{
Adriano A. Rampini ${ }^{\dagger}$ \\ Department of Finance, Kellogg School of Management, Northwestern University, \\ Evanston, IL 60208, USA
}

July 2003

\begin{abstract}
This paper analyzes a model in which the risk associated with entrepreneurial activity implies that the amount of such activity is procyclical and results in amplification and intertemporal propagation of productivity shocks. In the model risk averse agents choose between a riskless project and a risky project with higher expected output ('the entrepreneurial activity'). Agents who become entrepreneurs need to bear part of the project-specific risk for incentive reasons. More agents become entrepreneurs when productivity is high, because agents are more willing to bear risk and need to bear less risk for incentive reasons. Furthermore, cross-sectional heterogeneity can be countercyclical.
\end{abstract}

JEL classification: D82; E32; E44; G39

Keywords: Agency costs; Entrepreneurship; Risk aversion; Amplification; Propagation

*I thank Andrea Eisfeldt, Thomas Sargent, and José Scheinkman, as well as Andrew Abel, Malcolm Baker, Marco Bassetto, Alberto Bisin, Denis Gromb, Lars Hansen, Narayana Kocherlakota, Arvind Krishnamurthy, Deborah Lucas, Alexander Monge, Mitchell Petersen, Lars Stole, Robert Townsend, Richard Rogerson (the associate editor), an anonymous referee, seminar participants at the University of Chicago, the University of Pennsylvania (Wharton), the University of Colorado at Boulder, the 1999 SED Annual Meeting, the 1999 Workshop in Economic Theory (Venice), the 1999 SITE Summer Workshop, the 2000 World Congress of the Econometric Society, the 2001 NBER Summer Institute, the 2001 SAET Biennial Conference, and the 2002 AFA Annual Meeting for helpful comments. I gratefully acknowledge financial support from the University of Chicago and the Alfred P. Sloan Foundation.

${ }^{\dagger}$ Corresponding author. Address: Department of Finance, Kellogg School of Management, Northwestern University, 2001 Sheridan Road, Evanston, IL 60208. Phone: (847) 467-1841. Fax: (847) 491-5719. Email: rampini@northwestern.edu. 


\section{Introduction}

This paper analyzes a model of entrepreneurial activity and argues that entrepreneurial activity is procyclical due to the risk associated with it. Thus, a model with endogenous entrepreneurial activity may result in greater amplification and intertemporal propagation of aggregate shocks. We argue that the risk aversion of entrepreneurs, who can not fully diversify the idiosyncratic risk of their projects for incentive reasons, is an additional mechanism making economic activity more volatile. Considering entrepreneurial risk aversion is important since the economic activity of small firms is particularly affected by downturns ${ }^{1}$ and ownership of such firms is highly concentrated, typically in the hands of just one principal owner. ${ }^{2}$

We study an economy where risk averse agents face a choice between a riskfree project and a risky project which is more productive but requires an unobservable effort ('the entrepreneurial activity'). Thus, for incentive reasons, agents who take the risky project, i.e. entrepreneurs, need to bear part of the project-specific risk. Since agents are more willing to bear risk when productivity is high and, in fact, need to bear less risk for incentive reasons, entrepreneurial activity is procyclical even under the optimal contract. In other words, countercyclical agency costs imply that the more productive risky technology dominates the riskless one when productivity is sufficiently high. Thus, countercyclical agency costs result in agents' technology

\footnotetext{
${ }^{1}$ See Bernanke, Gertler, and Gilchrist (1996) who review the empirical evidence on the effect of economic downturns on the access to credit and the economic activity of 'high agency cost' borrowers, specifically small firms.

${ }^{2}$ Data from the 1993 National Survey of Small Business Finances suggests that the ownership share of the principal owner of businesses with less than 500 employees is $81 \%$. For evidence on the effect of entrepreneurial risk on portfolio choice see Heaton and Lucas (2000).
} 
choices being procyclical and hence amplify technology shocks.

Aggregate output can be quite sensitive to changes in the amount of entrepreneurial activity. The reason is that at a point where an agent is indifferent between the riskless and the risky project, the expected output of the risky project exceeds the output of the riskless project because agents have to be compensated for risk. Thus, changes in entrepreneurial activity can have a first order effect on output.

Furthermore, intertemporal smoothing through storage can make technology adoption correlated across time even if productivity shocks are independent. High storage has a similar effect to high productivity. The higher the amount carried over from the previous period, the better off agents are this period, which makes them more willing to bear project-specific risk and hence a larger fraction of them become entrepreneurs ceteris paribus. In addition, high productivity today implies both increased entrepreneurial activity today and increased storage for tomorrow, which in turn implies increased entrepreneurial activity tomorrow. Thus, the model implies intertemporal propagation, although this effect is relatively small quantitatively.

Under the optimal contract entrepreneurs need to bear a larger part of the projectspecific risk when productivity is low. This may be interpreted, as we will argue, as entrepreneurs being more leveraged in bad times. The fact that agents need to hold more project-specific risk in a downturn also implies that the cross-sectional variation of consumption can be countercyclical; there may be more inequality in bad times. This is of particular interest since countercyclical cross-sectional variation has recently gotten attention in the asset pricing literature as one way to reconcile asset pricing models with empirical evidence on asset returns. ${ }^{3}$

\footnotetext{
${ }^{3}$ See Mankiw (1986) and Constantinides and Duffie (1996) and, for empirical evidence, Heaton and Lucas (1996) and Storesletten, Telmer, and Yaron (1999).
} 
The model also has implications for differences across countries. We expect more productive economies to be better able to share project-specific risk and hence to have more entrepreneurial activity. In addition, this model predicts that an economy with a less developed financial market, e.g., an economy where agents have to bear all the project-specific risk, may have more volatile as well as lower output. Thus, financial development can be negatively related to output variability because entrepreneurial activity can be more volatile when the financial system is less developed. ${ }^{4}$

The model is in a similar spirit to Kihlstrom and Laffont (1979) who study an entrepreneurial model with roots in the work of Knight. In their model, more risk averse individuals become workers while the less risk averse become entrepreneurs. In our model, wealth effects imply that risk aversion varies over the business cycle, and as agents become less risk averse, more of them become entrepreneurs. Thus, we provide a business cycle frequency version of Knight's theory of entrepreneurship.

Banerjee and Newman (1991) analyze a model where agents face an occupational choice similar to the one in our paper in a study of the distribution of wealth. However, their results are quite different from ours since in their model it is the poorer agents who choose the risky project.

The interaction between financial contracting and aggregate economic activity through countercyclical agency costs has received considerable attention recently. ${ }^{5}$

\footnotetext{
${ }^{4}$ See, e.g., Greenwood and Jovanovic (1990) and Acemoglu and Zilibotti (1997), for models of the interaction between financial development and growth. See, e.g., King and Levine (1993) and Rajan and Zingales (1998) for empirical evidence.

${ }^{5}$ See Scheinkman and Weiss (1985) for an early model. Holmström and Weiss (1985) study a model in which the use of investment as a screening device amplifies technology shocks. Williamson (1987) studies a model with delegated monitoring in which the amount of 'credit rationing' fluctuates over the business cycle and propagates technology shocks.
} 
Following Bernanke and Gertler (1989), this literature studies the effects of countercyclical agency costs in models with costly state verification of risk-neutral entrepreneurs with limited liability à la Townsend (1979) and Gale and Hellwig (1985). ${ }^{6}$

We think that our model complements the existing literature on the effects of countercyclical agency costs by pointing out the procyclical nature of technology choice in environments where agency costs are countercyclical due to risk aversion. In our model it is the risk associated with the entrepreneurial activity rather than constraints on outside funding (due to the limited resources of the insider, i.e., the entrepreneur) that limits the amount of entrepreneurial activity.

The paper proceeds as follows. In Section 2 we describe the model and characterize the solution. In Section 3 we solve an example explicitly, compute certain moments of the example economy, and simulate the economy. We also discuss the cyclical properties of cross-sectional heterogeneity, or inequality, and provide a comparison of the properties of the economy under different regimes of financial intermediation. We conclude in Section 4.

\section{Model}

In this section we describe the model and characterize the solution of the optimal contracting problem for this economy. We study the optimal contracting problem because we are interested in the dynamics of an economy in which agents only hold

\footnotetext{
${ }^{6}$ See Bernanke, Gertler, and Gilchrist (1999) for a synthesis of the literature. Fuerst (1995), Carlstrom and Fuerst (1997), and Fisher (1999) study the quantitative implications of this class of models. See also Greenwald and Stiglitz (1993) for a related model. Kiyotaki and Moore (1997) study the effect of the need to collateralize loans on aggregates and Holmström and Tirole (1996, $1997,1998)$ the effect of the demand for liquidity.
} 
the part of project-specific risk which is necessary for incentive reasons. In other words, we think of financial intermediaries offering contracts, e.g. defaultable debt contracts, to entrepreneurs that expose them to the minimal amount of projectspecific risk required for them to supply effort towards the success of the project.

\subsection{Environment}

There is a continuum of agents with unit mass. Time is discrete. Let each agent's utility function $\mathcal{U}$ from a consumption process $c$ and an effort process $e$ be given by

$$
\mathcal{U}(c, e)=E\left[\sum_{t=0}^{\infty} \beta^{t} u\left(c_{t}-e_{t}\right)\right]
$$

and assume that the momentary utility function $u$ is strictly increasing and strictly concave and satisfies the following assumption:

Assumption 1 (DARA) The momentary utility function u exhibits decreasing absolute risk aversion, i.e., satisfies $\frac{\partial}{\partial x}\left(-\frac{u^{\prime \prime}(x)}{u^{\prime}(x)}\right)<0$.

Notice that we assume a specific form of non-separability of utility in consumption and effort. Effectively, effort is in terms of the consumption good. Effort can thus be interpreted as an unobservable investment that is required to operate the risky technology. While this assumption about preferences is sufficient to obtain procyclical entrepreneurial activity, it is not necessary. ${ }^{7}$ However, the specific form of the non-separability chosen simplifies the analysis considerably.

Each period, the agents can choose one of the following two technologies or projects: A riskless technology that returns $\omega+y$ with certainty ${ }^{8}$ and $\operatorname{costs}_{0}=0$

\footnotetext{
${ }^{7}$ Notice however that in particular the standard assumption of separability of preferences in consumption and effort would not in general deliver this result.

${ }^{8}$ The following alternative interpretation of the riskless technology is possible: The technology is risky as well but there is no moral hazard. The output is $\omega+\hat{y}$ with probability $p$ and $\omega$ with
} 
effort and a risky technology that returns $\omega+Y$ with probability $p$ and $\omega$ with probability $1-p$ given effort $e_{1}>0$ and $\omega$ with certainty given the low effort level $e_{0}=0$. The aggregate productivity or technology shock, denoted by $\omega$, shifts the output of both technologies by a constant. The reason for this assumption is explained below. We assume that the returns of the risky technology are independent across agents conditional on the aggregate technology shock. Clearly, only the case where $p Y-e_{1}>y$ is of interest so we take that as given.

Effort is unobservable and hence agents have to be induced to work which, given our assumptions, is optimal if an agent takes the risky project. Thus, agents need to bear project-specific or idiosyncratic risk if they take the risky project. Importantly, we rule out intertemporal incentive provision by assuming that agents' identity can not be tracked intertemporally. ${ }^{9}$ That is, we do not allow compensation of an agent at time $t$ to depend on the outcome of his project at $t-1$. Thus, we restrict incentive provision to be intratemporal. We make this assumption for tractability reasons only. The main results are preserved even with intertemporal incentive provision, although the effects are somewhat mitigated.

The technology shock $\omega$ follows a Markov process. The technology shock is observed at the beginning of each period. As stated above it shifts the output of both technologies by a constant. Given this assumption $\omega$ affects only expected returns without affecting variances. Hence, a higher $\omega$ is unambiguously preferable. probability $1-p$ where $\hat{y}$ satisfies $y=p \hat{y}$. Obviously, full insurance is optimal when agents choose this technology. This alternative interpretation could be adopted throughout the paper, but for clarity we will always refer to the first technology as riskless and the second as risky.

${ }^{9}$ The benefits of multiperiod contracts have been recognized (see Townsend, 1982, Rogerson, 1985, and Green, 1987). For models with multiperiod contracts and aggregate fluctuations see Gertler (1992) and Phelan (1994). 
In addition, the additive structure allows us to reduce the dimensionality of the problem from two to one state variable when we restrict attention to the case of technology shocks that are independent over time.

Finally, we also allow storage of the output: For simplicity, we assume that storage $s$ is chosen from the interval $s \in S=[0, \bar{s}]$ with $\bar{s}<+\infty$. We assume that storage is observable by the planner or financial intermediary. Thus, we can without loss of generality assume that the planner or financial intermediary decides on storage. This completes the description of the economic environment.

\subsection{Optimal contracting problem}

The problem of designing the optimal contract is the following: At the beginning of each period the planner, which we interpret as a financial intermediary, observes the technology shock for that period. The planner then chooses the fraction of the population to be assigned to each technology, the consumption allocation as a function of the technology assignment and output realization and the level of storage for the next period. Let us introduce the technology choice variable $\alpha$ which is the fraction of agents that choose or are assigned to the risky technology and restrict it to $\alpha \in[0,1]$. That is, agents participate in a lottery that assigns them either to a risky project or to a riskless project with probabilities $\alpha$ and $1-\alpha .{ }^{10}$ Finally, output is realized and agents get their consumption allocation. We are now ready to state

\footnotetext{
${ }^{10}$ One can interpret the lottery as all agents applying for funding of their risky projects, but only a fraction $\alpha$ of the funding proposals being accepted. Notice that Bernanke and Gertler (1989) introduce a similar lottery in their model.
} 
the Bellman equation for this economy:

$$
\begin{gathered}
v(\omega+s, \omega)=\max _{\alpha \in[0,1], c, c_{0}, c_{1} \in \Re, s^{\prime} \in S}\left\{\alpha E\left[u\left(\tilde{c}-e_{1}\right) \mid e_{1}\right]+(1-\alpha) u(c)\right. \\
\left.+\beta E\left[v\left(\omega^{\prime}+s^{\prime}, \omega^{\prime}\right) \mid \omega\right]\right\}
\end{gathered}
$$

subject to

$$
\alpha E\left[\tilde{c} \mid e_{1}\right]+(1-\alpha) c+s^{\prime} \leq \omega+s+\alpha p Y+(1-\alpha) y
$$

and

$$
E\left[u\left(\tilde{c}-e_{1}\right) \mid e_{1}\right] \geq u\left(c_{0}-e_{0}\right)
$$

The notation is as follows: The value function $v$ is a function of two state variables: $\omega+s$, the sum of the technology shock $\omega$ and the storage level $s$, and $\omega$, the technology shock. ${ }^{11}$ For agents assigned to the riskless technology the consumption $c$ is just a constant. For agents assigned to the risky technology the consumption is either $c_{0}$ or $c_{1}$ depending on whether the output of a given agent is low, i.e., $\omega$, or high, i.e., $\omega+Y$, respectively. We write $\tilde{c}$ for the random variable with realizations $c_{0}$ and $c_{1}$. Note that the momentary expected utility of agents assigned to the risky technology is conditional on the high effort level being induced, which by assumption is optimal. The resource constraint is required to hold in expectation only since there is no within period uncertainty at the level of the population.

For simplicity, we study the case where the technology shock $\omega$ follows a Markov chain on the state space $\omega \in \Omega=\left\{\omega_{1}, \ldots, \omega_{M}\right\}$ where $\omega_{m+1}>\omega_{m}, \forall m \in\{1, \ldots, M-$ 1\}. Furthermore, we assume that the technology shocks are independent across time, i.e., $\Pi\left(\omega_{m^{\prime}} \mid \omega_{m}\right)=\Pi\left(\omega_{m^{\prime}} \mid \omega_{m^{\prime \prime}}\right), \forall m, m^{\prime}, m^{\prime \prime}$, or $\Pi_{m, .}=\pi, \forall m \in\{1, \ldots, M\}$, where

\footnotetext{
${ }^{11}$ Equivalently we could choose $\omega$ and $s$ as the state variables. We do not do so since the appropriate state variable when technology shocks are independent is $\omega+s$.
} 


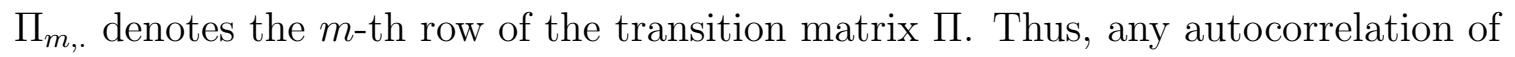
output or the amount of entrepreneurial activity that we obtain arises endogenously.

With the assumption of independence we can drop the second state variable and the Bellman equation can be written as

$$
v(\omega+s)=\max _{s^{\prime} \in S}\left\{\Phi^{c}\left(\omega+s-s^{\prime}\right)+\beta E\left[v\left(\omega^{\prime}+s^{\prime}\right)\right]\right\}
$$

where $\Phi^{c}$ is the expected utility generated in the current period given a value of the state variable net of storage $x$ and is defined as follows:

$$
\Phi^{c}(x) \equiv \max _{\alpha \in[0,1], c, c_{0}, c_{1} \in \Re}\left\{\alpha\left(p u\left(c_{1}-e_{1}\right)+(1-p) u\left(c_{0}-e_{1}\right)\right)+(1-\alpha) u(c)\right\}
$$

subject to

$$
\alpha\left(p c_{1}+(1-p) c_{0}\right)+(1-\alpha) c \leq x+\alpha p Y+(1-\alpha) y
$$

and

$$
p u\left(c_{1}-e_{1}\right)+(1-p) u\left(c_{0}-e_{1}\right) \geq u\left(c_{0}-e_{0}\right) .
$$

Thus we can solve the problem in two steps: First, we can analyze the one period technology adoption and contract design problem, which is the problem that defines $\Phi^{c}$. Then, taking $\Phi^{c}$ as given we can solve the dynamic problem. We study the one period technology adoption decision in the next subsection before we return to the dynamic problem.

\subsection{The one period technology adoption decision}

In order to understand the technology adoption decision it turns out to be convenient to study the momentary expected utility for a given aggregate technological choice, i.e., $\alpha=1$ or $\alpha=0$. For this purpose we introduce the following notation: Let $x$ denote the value of the state variable net of storage for the next period, i.e., net of $s^{\prime}$. 
Define $\Phi(x)$ as the expected momentary utility from choosing the risky technology as a function of $x$, i.e.,

$$
\Phi(x) \equiv \max _{c_{0}, c_{1} \in \Re}\left\{p u\left(c_{1}-e_{1}\right)+(1-p) u\left(c_{0}-e_{1}\right)\right\}
$$

subject to

$$
p c_{1}+(1-p) c_{0} \leq x+p Y
$$

and

$$
p u\left(c_{1}-e_{1}\right)+(1-p) u\left(c_{0}-e_{1}\right) \geq u\left(c_{0}-e_{0}\right) .
$$

Strict concavity of $\Phi$ is a desirable property for the analysis below. By assumption the utility function $u$ is strictly concave. The only concern in showing that $\Phi$ is strictly concave is, then, the convexity of the set of incentive compatible allocations. Proving convexity of that set is equivalent to proving that the certainty equivalent of a Bernoulli lottery is concave in the prizes. ${ }^{12}$ One can show that concavity of the certainty equivalent obtains for utility functions with constant absolute risk aversion and constant relative risk aversion. We restrict attention to the case of concave certainty equivalents for the rest of this paper:

\footnotetext{
${ }^{12}$ To see this equivalence, let $x=c_{1}-e_{1}, y=c_{0}-e_{1}$ and $w=c_{0}-e_{0}$. Note that $w-y=e_{1}-e_{0}$ and $x>y$. If the triple $(x, y, w)$ is incentive compatible then $p u(x)+(1-p) u(y) \geq u(w)$. Since $u(\cdot)$ is strictly increasing we can apply the inverse function $u^{-1}(\cdot)$ to this inequality to get $z \equiv$ $u^{-1}(p u(x)+(1-p) u(y)) \geq w$. The right hand side of the inequality is linear. Thus, it is necessary and sufficient that the certainty equivalent of the lottery with prizes $(x, y)$, which we denote by $z$ above, is concave in the prizes. Note finally that if $(x, y, w)$ and $\left(x^{\prime}, y^{\prime}, w^{\prime}\right)$ satisfy $x>y, x^{\prime}>y^{\prime}$, $w-y=e_{1}-e_{0}$ and $w^{\prime}-y^{\prime}=e_{1}-e_{0}$, then for $\lambda \in(0,1)$ we have $x_{\lambda}>y_{\lambda}$ and more importantly $w_{\lambda}-y_{\lambda}=e_{1}-e_{0}$ where $x_{\lambda} \equiv \lambda x+(1-\lambda) x^{\prime}$ and analogously for $y_{\lambda}$ and $w_{\lambda}$. Hence, if the first two allocations are admissible so is any convex combination.
} 
Assumption 2 The utility function $u$ satisfies the property that the certainty equivalent of a Bernoulli lottery is concave in the prizes.

By the theorem of the maximum ${ }^{13} \Phi$ is continuous and, thus, we have the following lemma:

Lemma 1 Suppose Assumption 1 and 2 hold. Then $\Phi$ is continuous and strictly concave.

The assumption of decreasing absolute risk aversion, i.e., Assumption 1, implies that if there is a reversal of the technology choice across the state space at all, then the risky technology is preferable for high values of $x$ and the riskless technology for low values of $x$. Furthermore, there is at most one reversal of the technology choice. This is stated formally in the next lemma:

Lemma 2 Suppose Assumption 1 holds. If $E\left[u\left(x^{\circ}+\tilde{Z}\right)\right] \geq u\left(x^{\circ}+\bar{Z}\right)$, then $E[u(x+$ $\tilde{Z})] \geq u(x+\bar{Z}), \forall x \geq x^{\circ}$.

This lemma is a direct implication of the definition of decreasing absolute risk aversion. The intuition is that the 'wealthier' the agent, i.e., the higher $x$, the less risk averse the agent. Thus, if an agent with a specific wealth level prefers a lottery over a fixed payment, so will all agents with a wealth level higher than that. To apply the lemma here, define $\tilde{Z}$ to be a random variable taking on values $Y-e_{1}$ and $-e_{1}$ with probabilities $p$ and $1-p$ and let $\bar{Z}=y$. This means that there is a threshold level of wealth such that all agents with a wealth level higher than that will become entrepreneurs. In other words, if an agent lived in autarky, he would become an entrepreneur only if his wealth level exceeded this threshold. Thus, if there were no

\footnotetext{
${ }^{13}$ See, e.g., Stokey and Lucas with Prescott (1989).
} 
insurance at all, entrepreneurial activity in this environment would be procyclical. The key question then is whether entrepreneurial activity remains procyclical, once optimal insurance through contracts offered by a financial intermediary is taken into account. The main result is that this is indeed the case: Entrepreneurial activity is procyclical even if agents have access to financial intermediaries.

More generally, we can ask what type of risk we should expect to be 'insurable.' Clearly, we do not expect aggregate risk to be insurable. Idiosyncratic risk, in contrast, should be insurable at least to the extent compatible with incentives. We show, however, that the 'insurability' of idiosyncratic risk varies with aggregates and, in fact, covaries positively with productivity in our model. Agency costs are hence countercyclical in the sense that more utility is lost due to the moral hazard problem when productivity is low.

The main result is summarized in the next proposition, which states that a result similar to Lemma 2 holds if optimal insurance is taken into account:

Proposition 1 Suppose Assumption 1 and 2 hold. If $\Phi\left(x^{*}\right) \geq u\left(x^{*}+y\right)$, then $\Phi(x) \geq u(x+y), \forall x \geq x^{*}$.

The proof is in the appendix. Proposition 1 implies that even under the optimal contract, an agent chooses to become an entrepreneur only if his wealth exceeds a certain threshold $x^{*}$. The intuition is as follows: Suppose an agent at wealth level $x^{*}$ prefers the entrepreneurial activity to the riskless activity given a contract offered by the financial intermediary. If an agent with a wealth level higher than that had access to the same contract (shifted by the difference in wealth), he would choose the entrepreneurial activity as well because he is less risk averse. But in fact one can do better than that and provide the richer agent with additional insurance (see the corollary to Proposition 1 below). 
By choosing whether or not to become an entrepreneur optimally as in Proposition 1, an agent can hence attain an expected utility of $\max \{u(x+y), \Phi(x)\}$. It turns out, however, that the set of expected utilities defined by $\{U: U \leq$ $\max \{u(x+y), \Phi(x)\}\}$ is not convex. The non-convexity is around the wealth level $x^{*}$ where the agent switches from the riskless project to the risky project. The agent's expected utility can thus be increased by convexifying the technology adoption decision in this range. Specifically, the agents sign up with an intermediary. The intermediary assigns a fraction $\alpha$ of the agents to the risky project, the rest to the riskless project. Who gets assigned to which project is determined by a lottery. The agents assigned to the risky project get a contract which is a good deal, i.e., there is cross-subsidization from the agents who run riskless projects to the agents who run risky projects. The intuition is that, loosely speaking, running a risky project and being rich are complements and hence it is optimal to give agents who are entrepreneurs a good deal.

Convexifying the technology adoption results in the expected utility frontier $\Phi^{c}(x)=c o(\{U: U \leq \max \{u(x+y), \Phi(x)\}\})$ where co stands for taking the convex hull. In practice we get $\Phi^{c}$ directly when solving the constrained optimization problem that defines $\Phi^{c}$ numerically. Obviously, the function $\Phi^{c}$ is by construction continuous and (weakly) concave. Notice that the implications for technology adoption carry over to the case where convexification is taken into account, i.e., entrepreneurial activity is procyclical even in this case. The only difference is that instead of a specific cut off level for wealth at which entrepreneurial activity starts, there is a range of wealth levels in which the fraction of agents who become entrepreneurs increases linearly from 0 to 1 (see the numerical illustration in the next section). We can interpret access to financial intermediaries which can enforce binding contracts 
that allow for ex post cross-subsidization as an economy being more financially developed. Thus, the model implies that financial development can reduce the volatility of output, a prediction that is empirically testable in a cross section of countries.

The model presented here has interesting implications for the variability of consumption across agents as a function of wealth. The variability of the consumption allocation associated with $\Phi$ is decreasing in $x$. In other words, if $c_{1}$ and $c_{0}$ solve the maximization problem defining $\Phi$ then $\Delta c \equiv c_{1}-c_{0}$ is decreasing in $x$. This is summarized in the following corollary to Proposition 1.

Corollary 1 The variability of the consumption allocation associated with $\Phi$ is decreasing in $x$, i.e., $\Delta c \equiv c_{1}-c_{0}$ is decreasing in $x$.

The proof is in the appendix. Thus, under the optimal contract entrepreneurs bear less risk when productivity is high or, in other words, incentives need to be steeper in bad times. In terms of claims traded in financial markets this means that insiders have to hold more of the equity in their projects when productivity is low. In good times, entrepreneurs are able to sell more equity to outsiders and hold more bonds, whereas in bad times they have to bear more risk, i.e., they obtain less outside financing of the risky part of their endeavor. We can alternatively interpret this as entrepreneurs being less leveraged when productivity is high, where we take 'less leverage' to mean holding a less risky stake, i.e., less project-specific risk born by the insider. Under this interpretation leverage is countercyclical which reflects the countercyclical nature of agency costs.

\subsection{Computation}

Given $\Phi^{c}$ from the previous subsection, we can now go back to the dynamic problem. Since $\Phi^{c}$ is a continuous and weakly concave function and taking $\Phi^{c}$ as given, 
standard arguments ${ }^{14}$ imply the following lemma:

Lemma 3 There exists a unique fixed point $v$ of the operator

$$
(T f)(\omega+s)=\max _{s^{\prime} \in S}\left\{\Phi^{c}\left(\omega+s-s^{\prime}\right)+\beta E\left[f\left(\omega^{\prime}+s^{\prime}\right)\right]\right\}
$$

and $v$ is continuous, strictly increasing and weakly concave.

Given concavity of $\Phi^{c}$ and $v$, the storage policy is (at least weakly) increasing in the value of today's state variable $\omega+s$, which the numerical illustrations corroborate.

The computation is in two steps: First, the function $\Phi^{c}$ is computed by solving the static optimization problem that defines that function numerically. Second, the dynamic programming problem is solved using the solution for $\Phi^{c}$ from step 1 as the return function. To compute the value function we follow Ljungqvist and Sargent (2000) and discretize the state space, more specifically the storage decision, by letting $s \in S=\left\{s_{1}, \ldots, s_{N}\right\}$ where $s_{1}=0, s_{N}=\bar{s}$ and $s_{n+1}=s_{n}+\bar{s} /(N-1)$, $\forall n \in\{1, \ldots, N-1\}$. Given aggregate productivity $\omega_{m}$ and storage level $s_{n}$ we can then write the dynamic program as

$$
(T v)\left(\omega_{m}, s_{n}\right)=\max _{s^{\prime} \in S}\left\{\Phi^{c}\left(\omega_{m}+s_{n}-s^{\prime}\right)+\beta \sum_{m^{\prime}=1}^{M} \Pi_{m m^{\prime}} v\left(\omega_{m^{\prime}}, s^{\prime}\right)\right\} .
$$

Define the $N \times N$-matrix $R_{m}$ by letting $R_{m}\left(n, n^{\prime}\right) \equiv \Phi^{c}\left(\omega_{m}+s_{n}-s_{n^{\prime}}\right)$ and the $N \times 1$-vector $v_{m}$ by letting $v_{m}(n) \equiv v\left(\omega_{m}, s_{n}\right)$. Then

$$
T v_{m}=\max \left\{R_{m}+\beta \sum_{m^{\prime}=1}^{M} \Pi_{m m^{\prime}} \iota v_{m^{\prime}}^{\top}\right\}
$$

or

$$
T v=\max \left\{R+\beta(\Pi \otimes \iota) v^{\top}\right\}
$$

\footnotetext{
${ }^{14}$ See, e.g., Stokey and Lucas with Prescott (1989).
} 
where $\iota$ is an $N \times 1$-vector of ones, $R \equiv\left(\begin{array}{c}R_{1} \\ \vdots \\ R_{M}\end{array}\right)$ and $v \equiv\left(v_{1}, \ldots, v_{M}\right)$. The Bellman equation can then be solved by iterating to convergence on the last expression.

\subsection{Accommodating growth}

Economic growth due to exogenous technological change can be easily accommodated in this model. To account for growth we can think of the size of both technologies and the productivity shocks as growing at a continuous growth rate of $g$, i.e., $Y_{t}=$ $\exp (g t) Y, y_{t}=\exp (g t) y, e_{1 t}=\exp (g t) e_{1}, e_{0 t}=\exp (g t) e_{0}$, and $\omega_{m t}=\exp (g t) \omega_{m}$, $m=1, \ldots, M$. If we further assume that the return on storage equals $\exp (g)$ and each agent's momentary utility function exhibits constant relative risk aversion, i.e., $u(c)=c^{1-\sigma} /(1-\sigma), \sigma>0$, then we can map the problem of the growing economy into the stationary problem solved above by letting $\tilde{c}_{t}=\exp (-g t) c_{t}, \tilde{s}_{t}=\exp (-g t) s_{t}$ and $\tilde{\beta}=\beta \exp (g(1-\sigma))$. Obviously, we can also reverse this mapping to simulate a growing economy once the solution for the stationary economy has been computed.

\section{A quantitative example}

In this section we compute an example economy to illustrate our model of information constrained contracting as a propagation mechanism. In addition, we characterize the cyclical properties of cross-sectional heterogeneity and compare economies which differ in the degree of financial development. 


\subsection{Parameterization}

The parameters of the example economy are chosen to demonstrate the main effects of entrepreneurial risk on economic activity rather than being calibrated to match specific moments of an economy. However, to tie our hands the productivity shock process is chosen to match the empirical standard deviation of total factor productivity of about $1 \%$ (see, e.g., King and Rebelo, 1999) and the preference parameters are standard. The parameterization of the example economy, as well as the results, are summarized in Table 1 . The rate of time preference $\beta$ is 0.99 and hence a period corresponds to one quarter. Preferences exhibit constant relative risk aversion, i.e., $u(c)=c^{1-\sigma} /(1-\sigma)$ with a coefficient of relative risk aversion $\sigma=2$. We next discuss the parameters of the production technology which are chosen such that the expected output of the risky technology net of effort cost implied by the model is about $11 \%$ higher than that of the riskless one. Recall that the output of the riskless technology is $\omega+y$. We set $y=0.27$. The output of the risky technology is $\omega+Y$ with probability $p$ and $\omega$ otherwise, where $Y=1.1$ and $p=0.5$. The high effort is $e_{1}=0.19$ (and recall that $e_{0}=0$ ). The technology shocks are described by a Markov chain with $M=5$, i.e., 5 states, which are equally spaced around a mean of 0.5325 with $\Delta_{\omega} \equiv \omega_{m}-\omega_{m-1}=0.011, \forall m \in\{2, \ldots, 5\}$. Technology shocks are independent over time with distribution $\pi=[0.0625,0.25,0.375,0.25,0.0625]$, i.e, a symmetric, binomial distribution, and thus the standard deviation of technology shocks is $\sigma(\omega)=\Delta_{\omega}=0.011$. It is important to notice that while we refer to $\omega$ as the 'technology shock' throughout the paper which simplifies the exposition, this is not equivalent to 'productivity' in the sense of total factor productivity. An appropriate way to define and measure productivity and the variability of productivity in our model is by looking at the expected output of the risky technology and its standard 
deviation since the technologies are linear in the model. Denote the output of the risky technology by $\mathcal{Y}_{\text {risky }}$. The expected output is $E\left[\mathcal{Y}_{\text {risky }}\right]=E[\omega]+p Y=1.0825$ and, because of the additive structure, the standard deviation is $\sigma\left(\mathcal{Y}_{\text {risky }}\right)=0.011$. Thus, productivity has a standard deviation of about $1 \%$ as desired.

Finally, the storage technology is specified by $N=25$ and $\bar{s}=0.066$. This upper bound on storage is not binding in equilibrium.

[Table 1 about here.]

\subsection{Results}

To illustrate the technology choice problem we graph the expected one period utility for each technology choice as a function of $x$, the technology shock net of storage in the left panel of Figure 1. That is we graph the functions $u(x+y)$ and $\Phi(x)$ as a function of $x$. The riskless technology dominates the risky technology only for low values of $x$. The solid line shows the expected utility once convexification is taken into account. For very low $x$ only the riskless project is optimally chosen. For $x$ in a middle range a convex combination of the two projects is assigned with the weight $\alpha$ on the risky project increasing in $x$ (see the right panel of Figure 1). Finally, for $x$ sufficiently high all the agents are assigned to the risky project.

[Figure 1 about here.]

Following Ljungqvist and Sargent (2000) we compute the value function and the optimal policy, i.e., the optimal technology adoption policy and the optimal storage policy. An optimal policy is a pair of mappings $\left(\alpha^{*}, s^{*}\right)$ where $\alpha^{*}: \Omega \times S \mapsto[0,1]$ and $s^{*}: \Omega \times S \mapsto S$. For the example under consideration the optimal policy implies that all agents take the risky technology when productivity is high, but entrepreneurial 
activity drops when productivity is low. For the lowest productivity level and given zero storage, entrepreneurial activity drops from an average level of $86 \%$ to $57 \%$.

With the characterization of the optimal policy in hand we are ready to calculate the moments of the example economy and simulate the economy using the Markov matrix $\Pi^{*}$ induced by the optimal policy $\left(\alpha^{*}, s^{*}\right)$ and the associated invariant distribution $p^{*}$.

By construction, the technology shock has a mean $E[\omega]=0.5325$ and a standard deviation $\sigma(\omega)=0.011$. The conditional expectation of the output of a given technology has the same standard deviation as the technology shock. We argued that an appropriate measure of productivity is the conditional expectation of the output of the risky technology normalized by the unconditional expectation of the output of that technology which we display for a simulation of the example economy in Figure 2. The unconditional expectation of output $\mathcal{Y}$ of the economy is $E[\mathcal{Y}]=1.0437$ with a standard deviation of $\sigma(\mathcal{Y})=0.0462$. The endogeneity of technology choice amplifies productivity shocks. In fact, the standard deviation of output (in percentage terms) is about 4 times the standard deviation of productivity. Figure 2 provides a simulation of the example which illustrates this amplification. Since we study a model in which preferences are not separable in consumption and effort, one might argue that output should be corrected for effort cost. The standard deviation of output net of effort cost is $\sigma\left(\mathcal{Y}-e^{*}\right)=0.0342$ where $e^{*}$ denotes the optimal effort, a random variable that equals $e_{1}$ for the fraction of the population assigned to the risky technology and $e_{0}$ for the rest of the population. This reflects amplification of about 3.5 times the standard deviation of productivity even after adjusting for effort cost. Finally, the correlation between output in period $t$ and $t-1$ is $\rho\left(\mathcal{Y}_{t}, \mathcal{Y}_{t-1}\right)=0.0500$, i.e., output is autocorrelated despite independent technology shocks, although this 
effect is small in this specification. This effect is likely to remain relatively small in general, since it is a version of the 'capital accumulation' mechanism which is well known to be a quantitatively unimportant source of persistence. The reason for the positive autocorrelation is that high productivity at time $t-1$ increases not only entrepreneurial activity and hence output at time $t-1$ but storage from time $t-1$ to time $t$ is higher as well, which means that agents are better off at time $t$ and, thus, there is more entrepreneurial activity and higher output at time $t$, too. Similarly, when we correct for effort, the autocorrelation of output net of effort cost is $\rho\left(\mathcal{Y}_{t}-e_{t}^{*}, \mathcal{Y}_{t-1}-e_{t-1}^{*}\right)=0.0470$. However, any cost in adjusting the fraction of agents who become entrepreneurs would add additional persistence. If this cost is furthermore asymmetric, i.e., if it is easier to reduce the amount of entrepreneurial activity than to increase it, due to, e.g., search frictions, than such propagation is likely to be asymmetric as well with short downturns and long recoveries. This would be interesting to explore, but is beyond the scope of this paper.

[Figure 2 about here.]

It is worth noting that output contracts considerably when productivity is low and agents move out of the risky technology. At the lowest level of productivity, productivity is $2 \%$ below average while output is about $10 \%$ below average, since entrepreneurial activity drops to $57 \%$ from an average of $86 \%$. The reason is that at a point where an agent is indifferent between the riskless project and the risky project, the expected output of the risky project exceeds the output of the riskless project, since the agent has to be compensated for the utility loss due to risk. Thus, when entrepreneurs switch to the riskless project this has a first order effect on average output. 


\subsection{Cross-sectional heterogeneity}

The optimal contract has interesting implications for the cyclicality of inequality in our economy. Inequality in terms of expected utility before agents are assigned to a technology is completely absent. The variance of output across agents is increasing in the fraction of the population assigned to the risky project and hence procyclical. However, this is not the case for the cross-sectional variance of consumption. In general, the cross-sectional variance of consumption is non-monotone in $x$, the state variable net of storage, since if all agents take the riskless project the cross-sectional variation is zero whereas Corollary 1 implies that when all agents take the risky project the cross-sectional variation is decreasing in $x$. In the example studied in this section the cross-sectional variance of consumption is countercyclical. The correlation between the cross-sectional variance of consumption and output is about -0.46 .

The cross-sectional variance net of effort cost is non-monotone in general as well and turns out to be procyclical in our example which seems interesting by itself. In terms of the implications for empirical work this means that it is hence important not only to adjust 'income' (output) for partial insurance to get 'consumption' but also to decide whether and how to account for 'effort'. Ultimately, the measure of ex post inequality that should be sought is one that accounts for both partial insurance and effort cost.

Thus, the model of entrepreneurial activity presented here provides not just an additional amplification mechanism, but also an explanation for counter-cyclical cross-sectional heterogeneity which has recently gotten attention in the asset pricing literature. 


\subsection{Different regimes of financial intermediation}

It is interesting to compare the economy above to an equivalent economy with a less developed financial market, e.g., an economy where financial intermediaries can not enforce ex-post cross-subsidization and hence lotteries are absent. In such an economy, entrepreneurial activity is either $0 \%$ or $100 \%$, and hence can be quite volatile. Proceeding as before, ${ }^{15}$ the standard deviation of output in this financially less developed economy is 0.1001 , which is about 2 times the standard deviation of output in the economy with lotteries. Thus, output volatility is higher in the economy with a less developed financial system. This is because when productivity is very low, entrepreneurial activity stops and output contracts by as much as $25 \%$. At the same productivity, output in the economy with a developed financial system is only $10 \%$ below average. Thus, the output dynamics of the two economies with different financial intermediation regimes differ considerably and financial development is negatively related to output variability. ${ }^{16}$

\section{Conclusions}

In a model where agents can choose to enter an entrepreneurial activity which is risky and where project-specific risk can not be perfectly diversified away for incentive reasons, we obtain amplification and intertemporal propagation of productivity

\footnotetext{
${ }^{15}$ Notice that the return function in this case is not (weakly) concave, but this does not seem to be a problem computationally in the example studied here.

${ }^{16}$ If there were no financial intermediation at all and agents had to bear all project-specific risk in this economy, then there would be no entrepreneurial activity and hence no amplification or propagation. Thus, output variability is non-monotone in financial development in general.
} 
shocks, although the intertemporal propagation is small quantitatively. Countercyclical agency costs resulting from decreasing absolute risk aversion are responsible for amplification and intertemporal propagation in our model. Absent asymmetric information or risk aversion the technology choice would be independent of the aggregate state and there would be neither amplification nor intertemporal propagation. If, however, agents were forced to bear all project-specific risk in our economy, entrepreneurial activity would be procyclical. What we show in this paper is that entrepreneurial activity remains procyclical even if agents can share as much of the entrepreneurial risk as is compatible with incentives. When productivity is high, agents are not only willing to bear more idiosyncratic risk but in fact are also able to share a larger fraction of that risk with outsiders in our model. Thus, in a sense insiders are more able to sell equity in their projects when productivity is high. The extent to which project-specific risk is insurable hence covaries positively with aggregates and makes entrepreneurial activity relatively more attractive in a boom and relatively less attractive in a downturn. We think that our model complements the existing literature on the effects of countercyclical agency costs (e.g., Bernanke and Gertler, 1989) by extending the theory of entrepreneurship based on risk aversion to a business cycle context and arguing that the risk associated with entrepreneurial activity is an additional force rendering entrepreneurial activity procyclical. We explore the implications of the model for the cyclicality of heterogeneity and show that we can obtain countercyclical cross-sectional variation. The focus of the paper is on the business cycle implications of the model for a single economy, but the model also has cross-sectional implications. In particular, the model predicts that economies with higher productivity are better able to share specific risk and hence have more entrepreneurial activity. Furthermore, financial development can decrease 
the variability of output as well as inequality. 


\section{Appendix}

Proof of Proposition 1. Let $\left(c_{1}^{*}, c_{0}^{*}\right)$ be the optimal consumption allocation associated with $x^{*}$. Take $x>x^{*}$. Define $\Delta \equiv x-x^{*}>0$. Consider $\hat{c}_{1}=c_{1}^{*}+\Delta$ and $\hat{c}_{0}=c_{0}^{*}+\Delta$ which is clearly feasible at $x$. Incentive compatibility of $\left(c_{1}^{*}, c_{0}^{*}\right)$ at $x^{*}$ together with Lemma 2 implies:

$$
p u\left(c_{1}^{*}+\Delta-e_{1}\right)+(1-p) u\left(c_{0}^{*}+\Delta-e_{1}\right) \geq u\left(c_{0}^{*}+\Delta-e_{0}\right),
$$

i.e., $\left(\hat{c}_{1}, \hat{c}_{0}\right)$ is incentive compatible at $x$. But then $\Phi\left(x^{*}\right) \geq u\left(x^{*}+y\right)$ implies again by Lemma 2 that

$$
p u\left(c_{1}^{*}+\Delta-e_{1}\right)+(1-p) u\left(c_{0}^{*}+\Delta-e_{1}\right) \geq u\left(x^{*}+\Delta+y\right),
$$

and hence, since $\Phi(x)$ (weakly) exceeds the left hand side, the conclusion obtains.

Proof of Corollary 1. Let $\left(c_{1}^{*}, c_{0}^{*}\right)$ and $\left(\hat{c}_{1}, \hat{c}_{0}\right)$ be as in the proof of the proposition and let $\left(c_{1}, c_{0}\right)$ be the optimal consumption allocation associated with $x$. Suppose $c_{1}-c_{0}>c_{1}^{*}-c_{0}^{*}$. Then $c_{0}<\hat{c}_{0}$ since by Lemma 4 the resource constraint must be

binding at a solution and hence $\left(c_{1}, c_{0}\right) \geq\left(\hat{c}_{1}, \hat{c}_{0}\right)$ and $\left(c_{1}, c_{0}\right) \neq\left(\hat{c}_{1}, \hat{c}_{0}\right)$ is not feasible. But by Lemma 5 the incentive compatibility constraint is binding at a solution which implies that the value of the objective evaluated at $\left(c_{1}, c_{0}\right)$ is lower than the value at $\left(\hat{c}_{1}, \hat{c}_{0}\right)$ since the right hand side of the incentive compatibility constraint decreased. A contradiction.

Lemma 4 At a solution to the maximization problem defining $\Phi$ the resource constraint is binding.

Proof. Suppose not. Then it is feasible to increase $c_{1}$ which is also incentive compatible and increases the value of the objective. A contradiction. 
Lemma 5 At a solution to the maximization problem defining $\Phi$ the incentive compatibility constraint is binding.

Proof. Suppose not. Consider the following feasible variation: $\hat{c}_{1}=c_{1}^{*}-\varepsilon / p$ and $\hat{c}_{0}=c_{0}^{*}+\varepsilon /(1-p)$ where the pair $\left(c_{1}^{*}, c_{0}^{*}\right)$ denotes the original solution. Then $\left(c_{1}^{*}, c_{0}^{*}\right)$ is riskier than $\left(\hat{c}_{1}, \hat{c}_{0}\right)$ in the sense of Rothschild and Stiglitz (1970) since $\int_{0}^{y} F^{*}(c) d c \geq \int_{0}^{y} \hat{F}(c) d c, \forall y$, where $F^{*}(\cdot)$ and $\hat{F}(\cdot)$ are the cumulative distribution functions induced by the random variables $c^{*}$ and $\hat{c}$ respectively. Hence, the variation is an improvement. For $\varepsilon$ sufficiently small the variation is also incentive compatible which contradicts optimality of $\left(c_{1}^{*}, c_{0}^{*}\right)$. 


\section{References}

Acemoglu, D., Zilibotti, F., 1997. Was Prometheus unbound by chance? Risk, diversification, and growth. Journal of Political Economy 105, 709-751.

Banerjee, A., Newman, A., 1991. Risk-bearing and the theory of income distribution. Review of Economic Studies 58, 211-235.

Bernanke, B., Gertler, M., 1989. Agency costs, net worth, and business fluctuations. American Economic Review 79 (1), 14-31.

Bernanke, B., Gertler, M., Gilchrist, S., 1996. The financial accelerator and the flight to quality. Review of Economics and Statistics 78, 1-15.

Bernanke, B., Gertler, M., Gilchrist, S., 1999. The financial accelerator in a quantitative business cycle framework. In: Taylor, J., Woodford, M., eds., Handbook of Macroeconomics, Vol. 1C (North Holland, Amsterdam) 1341-1393.

Carlstrom, C., Fuerst, T., 1997. Agency costs, net worth, and business fluctuations: a computable general equilibrium analysis. American Economic Review 87, 893-910.

Constantinides, G., Duffie, D., 1996. Asset pricing with heterogeneous consumers. Journal of Political Economy 104, 219-240.

Fisher, J., 1999. Credit market imperfections and the heterogeneous response of firms to monetary shocks. Journal of Money, Credit, and Banking 31, 187-211.

Fuerst, T., 1995. Monetary and financial interactions in the business cycle. Journal of Money, Credit, and Banking 27, 1321-1338. 
Gale, D., Hellwig, M., 1985. Incentive-compatible debt contracts: the one-period problem. Review of Economic Studies 52, 647-663.

Gertler, M., 1992. Financial capacity and output fluctuations in an economy with multi-period financial relationships. Review of Economic Studies 59, 455-472.

Green, E., 1987. Lending and the smoothing of uninsurable income. In: Prescott, E., Wallace, N., eds., Contractual Arrangements for Intertemporal Trade (University of Minnesota Press, Minneapolis) 3-25.

Greenwald, B., Stiglitz, J., 1993. Financial market imperfections and business cycles. Quarterly Journal of Economics 108, 77-114.

Greenwood, J., Jovanovic, B., 1990. Financial development, growth, and the distribution of income. Journal of Political Economy 98, 1076-1107.

Heaton, J., Lucas, D., 1996. Evaluating the effects of incomplete markets on risk sharing and asset pricing. Journal of Political Economy 104, 443-487.

Heaton, J., Lucas, D., 2000. Portfolio choice and asset prices: the importance of entrepreneurial risk. Journal of Finance 55, 1163-1198.

Holmström, B., Tirole, J., 1996. Modeling aggregate liquidity. American Economic Review 86(2), 187-191.

Holmström, B., Tirole, J., 1997. Financial intermediation, loanable funds, and the real sector. Quarterly Journal of Economics 112, 663-691.

Holmström, B., Tirole, J., 1998. Private and public supply of liquidity. Journal of Political Economy 106, 1-40. 
Holmström, B., Weiss, L., 1985. Managerial incentives, investment, and aggregate implications: scale effects. Review of Economic Studies 52, 403-425.

Kihlstrom, R., Laffont, J.-J., 1979. A general equilibrium entrepreneurial theory of firm formation based on risk aversion. Journal of Political Economy 87, 719-748.

King, R., Levine, R., 1993. Finance and growth: Schumpeter might be right. Quarterly Journal of Economics 108, 713-737.

King, R., Rebelo, S., 1999. Resuscitating real business cycles. In: Taylor, J., Woodford, M., eds., Handbook of Macroeconomics, Vol. 1B (North Holland, Amsterdam) 927-1007.

Kiyotaki, N., Moore, J., 1997. Credit cycles. Journal of Political Economy 105, $211-248$.

Ljungqvist, L., Sargent, T., 2000. Recursive Macroeconomic Theory (MIT Press, Cambridge).

Mankiw, N. G., 1986. The equity premium and the concentration of aggregate shocks. Journal of Financial Economics 17, 211-19.

Phelan, C., 1994. Incentives and aggregate shocks. Review of Economic Studies 61, 681-700.

Rajan, R., Zingales, L., 1998. Financial dependence and growth. American Economic Review 88, 559-586.

Rogerson, W., 1985. Repeated moral hazard. Econometrica 53, 69-76. 
Rothschild, M., Stiglitz, J., 1970. Increasing risk I: a definition. Journal of Economic Theory 2, 225-243.

Scheinkman, J., Weiss, L., 1985. Borrowing constraints and aggregate economic activity. Econometrica 54, 23-45.

Stokey, N., Lucas, R., with Prescott, E., 1989. Recursive Methods in Economic Dynamics (Harvard University Press, Cambridge).

Storesletten, K., Telmer, C., Yaron, A., 1999. Asset pricing with idiosyncratic risk and overlapping generations. Mimeo, Carnegie Mellon University.

Townsend, R., 1979. Optimal contracts and competitive markets with costly state verification. Journal of Economic Theory 21, 265-293.

Townsend, R., 1982. Optimal multiperiod contracts and the gain from enduring relationships under private information. Journal of Political Economy 60, 11661186.

Williamson, S., 1987. Financial intermediation, business failures, and real business cycles. Journal of Political Economy 95, 1196-1216. 
Table 1

Parameterization and Results for the Example Economy

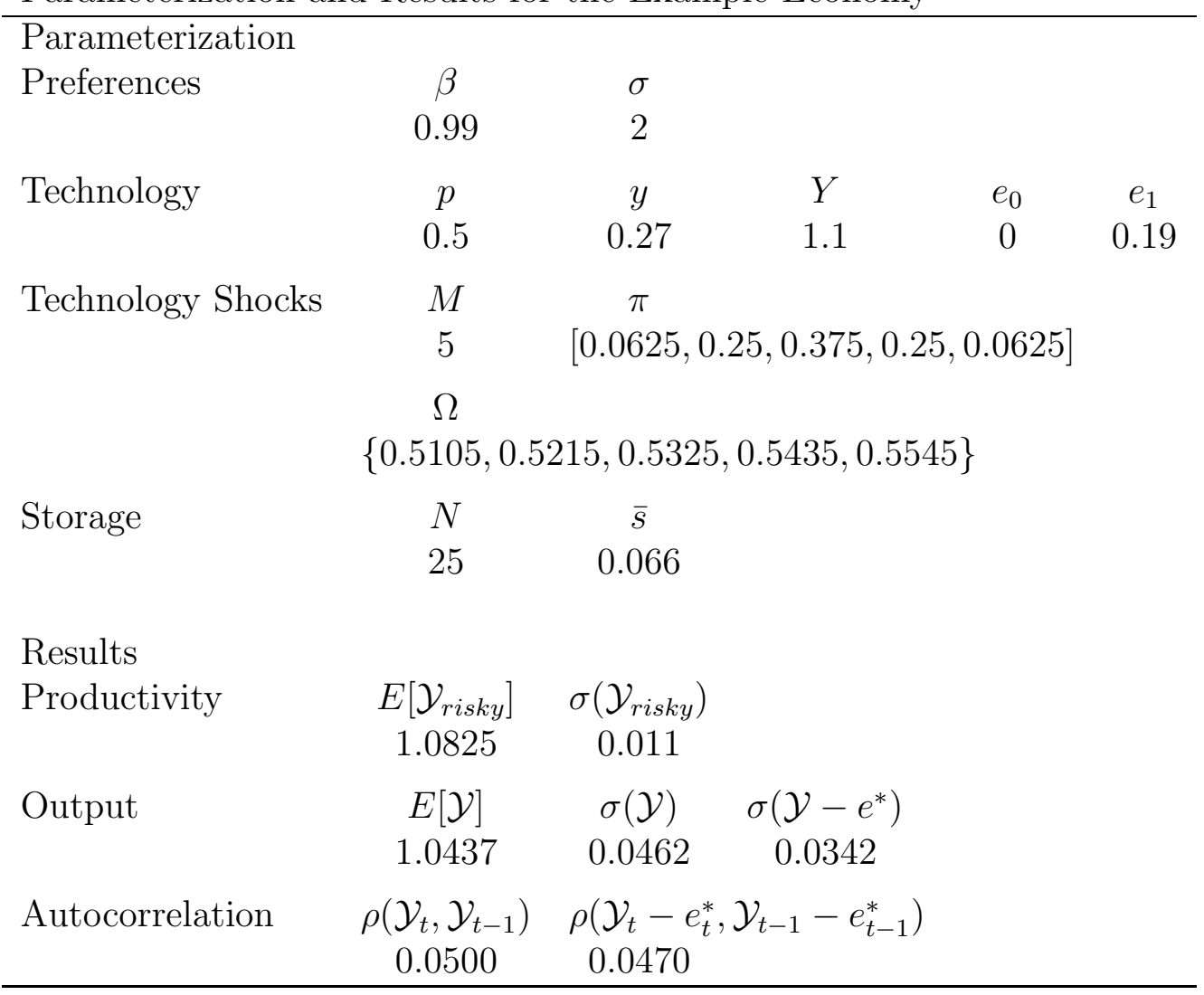


Figure 1: Expected One Period Utility for Riskless Technology, Risky Technology, and Convexified and Fraction of Agents Taking Risky Technology
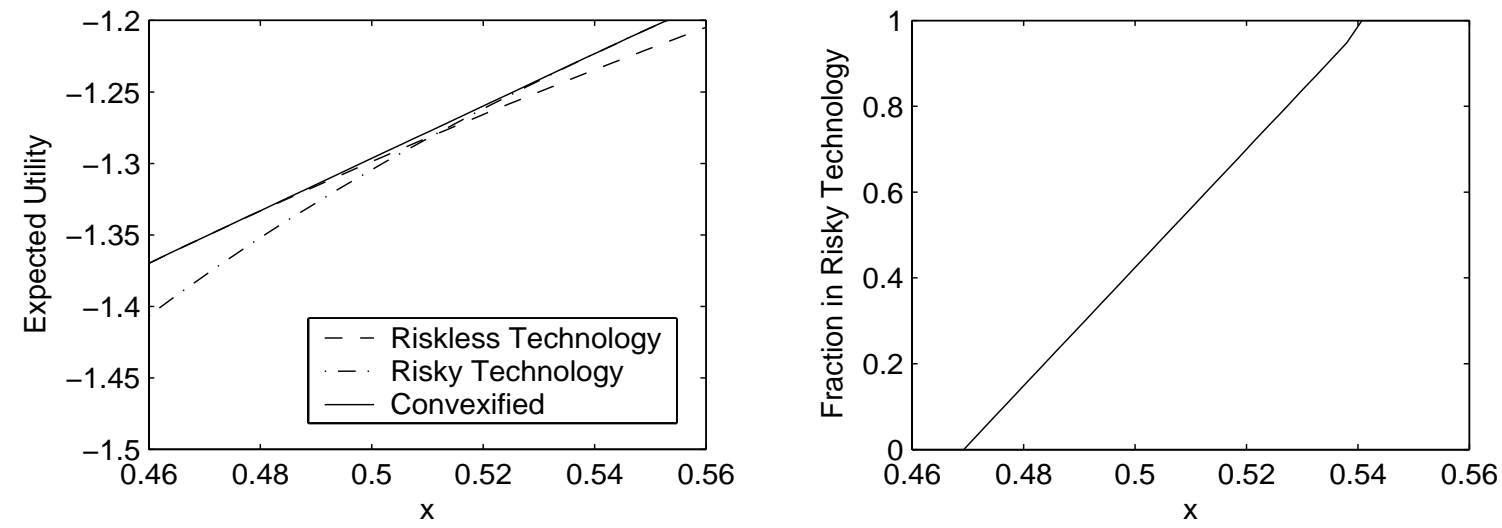
Figure 2: Simulation of Output and Productivity for the Example Economy

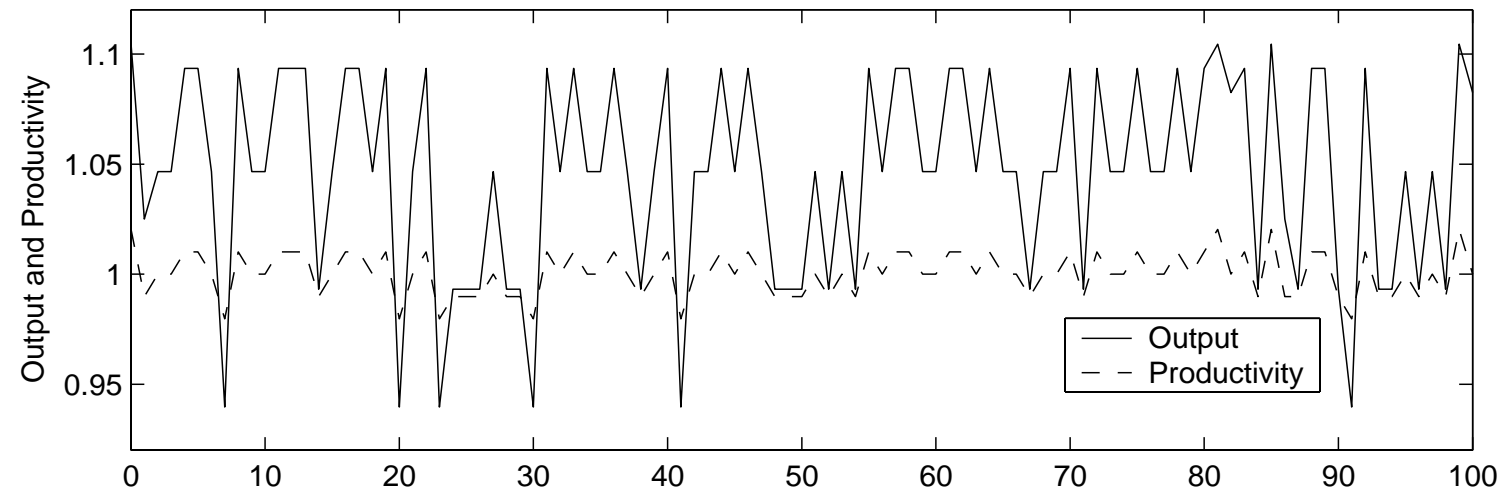

